\title{
Pentacene-Based Thin Film Transistor with Inkjet-Printed Nanocomposite High-K Dielectrics
}

\author{
Chao-Te Liu, Wen-Hsi Lee, and Jui-Feng Su \\ Department of Electrical Engineering, National Cheng Kung University, Tainan 70101, Taiwan \\ Correspondence should be addressed to Wen-Hsi Lee, leewen@mail.ncku.edu.tw
}

Received 15 August 2011; Accepted 11 November 2011

Academic Editor: Hsiao W. Zan

Copyright () 2012 Chao-Te Liu et al. This is an open access article distributed under the Creative Commons Attribution License, which permits unrestricted use, distribution, and reproduction in any medium, provided the original work is properly cited.

The nanocomposite gate insulating film of a pentacene-based thin film transistor was deposited by inkjet printing. In this study, utilizing the pearl miller to crumble the agglomerations and the dispersant to well stabilize the dispersion of nano- $\mathrm{TiO}_{2}$ particles in the polymer matrix of the ink increases the dose concentration for pico-jetting, which could be as the gate dielectric film made by inkjet printing without the photography process. Finally, we realized top contact pentacene-TFTs and successfully accomplished the purpose of directly patternability and increase the performance of the device based on the nanocomposite by inkjet printing. These devices exhibited $\mathrm{p}$-channel TFT characteristics with a high field-effect mobility (a saturation mobility of $\sim 0.58 \mathrm{~cm}^{2} \mathrm{~V}^{-1} \mathrm{~s}^{-1}$ ), a large current ratio $\left(>10^{3}\right)$ and a low operation voltage $(<6 \mathrm{~V})$. Furthermore, we accorded the deposited mechanisms which caused the interface difference between of inkjet printing and spin coating. And we used XRD, SEM, Raman spectroscopy to help us analyze the transfer characteristics of pentacene films and the performance of OTFTs.

\section{Introduction}

Organic thin film transistors (OTFTs) for display recently have been studied widely because of potential application in low cost, large area, and suiting for flexible electronics. They can be fabricated by simple soluble processes. However, the field mobility of OTFTs is lower and the threshold voltage is higher than that of the amorphous $\mathrm{Si}(\mathrm{a}-\mathrm{Si}) \mathrm{TFTs}$. Gate dielectrics plays a significant role in modifying the ameliorating of a field effect OTFTs $[1,2]$. Currently, high$\mathrm{k}$ materials are other ideal candidates and most of them are based on inorganic ceramic, which require widely expensive deposition process and higher annealing temperature. One way is to combine the advantages of inorganic high- $\mathrm{k}$ nanoparticles with organic soluble polymers to form the nanocomposite dielectrics [2-7]. The nanocomposite (NC) film is incompetent for photography to pattern as insulators of active matrix arrays and was introduced consequently into some new direct printing technology such as inkjet printing.

Recently, inkjet printing (IJP) process has been developed for electrical devices and become a promising instrument for the display industry because of the possibility in mask-free process and patternablility for nanoscale. In this study, we investigated the correlation of characteristics of printed NCfilms with various solid phases which affects the performance of O-TFTs application. We mixed cross-linked poly-4 vinyl phenol (PVP) solution and nanoparticles of $\mathrm{TiO}_{2}$ by pearl milling to attaining to increase the dielectric constant of gate insulator. Furthermore, the nanocomposite film based on the metal-insulator-metal (MIM) structure by inkjet printing achieves a high dielectric constant and low leakage current comparable to that by spin coating [2].

\section{Experiments}

2.1. Preparation of Inorganic-Organic Composite. The crosslinked PVP (Mw 25,000, from Aldrich) (9 wt \%) and crosslinking reagent poly-(melamine-co-formaldehyde) methylated (PMCF, $\mathrm{Mw}=511$, from Aldrich) (4 wt\%) dissolved in propylene glycol monomethyl ether acetate (PGMEA) were selected as the polymer matrix in which titanium dioxide $\left(\mathrm{TiO}_{2}\right)$ nanoparticles, a high-k material (Hombitan RM300, $\mathrm{k}=114,15 \mathrm{~nm}$ ), were uniformly dispersed. Ceramic slurry was well dispersed with the surface modified nano$\mathrm{TiO}_{2}$ particles by using $2 \mathrm{wt} \%$ dispersant (polysester) in PGMEA after pearl milling for $15 \mathrm{~min}$ at $2800 \mathrm{rpm}$, and 


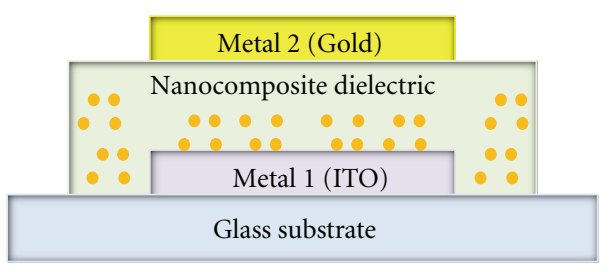

(a)

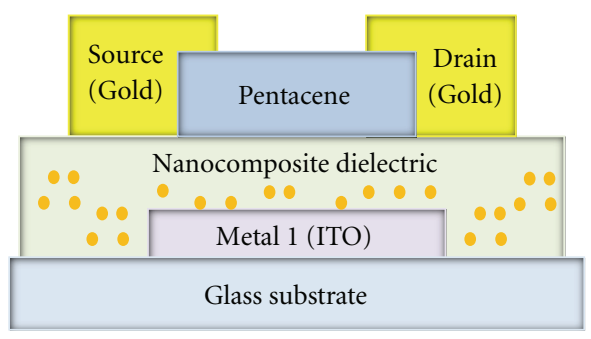

(b)

Figure 1: (a) The MIM structure of $\mathrm{TiO}_{2}-\mathrm{PVP}$ nanocomposite gate dielectric. (b) Configuration of "Bottom Gate" and "Top Contact" structure of an OTFT with the nanocomposite gate dielectric.

subsequently blending the slurry of $\mathrm{TiO}_{2}$ nanoparticles into cross-linked PVP solution which adjusted the concentration of the blended $\mathrm{TiO}_{2}$ nanoparticles.

2.2. Fabrication of Devices. Figure 1 presents two configurations of devices fabricated in this work. Nanocomposite dielectric layers were used to form a metal-insulator-metal (MIM) structure and also a bottom-contact TFT device. The thickness of indium-tin oxide (ITO) layer was thermally deposited for about $100 \mathrm{~nm}$ as a gate electrode on the glass substrate. After cleaning the glass with acetone in an ultrasonic bath, the nanocomposite film on ITO glass substrates was inkjet-printed with a thickness of 300-400 nm from the filtered (0.45-um PTFE filter) compound slurry and then baked at $190^{\circ} \mathrm{C}$ for $30 \mathrm{~min}$. The printer was piezoelectric drop-on-demand (DOD) inkjet printer (DMC2800, DIMATIX Corp.), and the spherical droplets were jetted to form a flat insulating layer. To obtain the leakage current density and dielectric constant, gold was thermally evaporated through the shadow mask and used as cover electrodes for the metal-insulator-metal (MIM) structure. For the top-contact OTFT structure, a $200 \mathrm{~nm}$ thick pentacene film was deposited as an organic semiconductor layer at deposition rate of $6 \mathrm{~nm} / \mathrm{s}$ on the nanocomposite gate dielectric film under about $1.6 \times 10^{-6}$ torr. Finally, gold was thermally evaporated through another shadow mask with channel $W / L=2$ as drain and source contacts.

2.3. Measurements. The thickness and roughness of the films were measured by a DI 3100 series atomic force microscope (AFM). The current-voltage $(I-V)$ characteristics of MIM were measured by an HP 4156A semiconductor parameter analyzer. The capacitance measurements were conducted with a HP 4284 A Precision LCR meter. The surface microstructures of the pentacene films on the dielectrics were characterized using a scanning electron microscope (SEM, XL-40FEG, Philips).

Raman spectrometer was used to characterize and compare the films quality, which can examine the relationship of the mobility and molecular vibrating.

\section{Results and Discussion}

3.1. Characteristics of Nanocomposite Gate Dielectric. Due to excellent stabilities in atmosphere environment and promising leakage current property [8], PVP dielectric was chosen as the matrix polymer. After the doped particles were separated more effectively by pearl-milling and dispersant of $2 \mathrm{wt} \%$ to nanosized dimensions about $26 \mathrm{~nm}$, the surface to volume ratio area of the particles would be substantially higher, and consequently the dispersive particles tend to agglomerate more easily by van der Waals forces as well as Brownian motion during the dispersive process [9]. The jetting stability dependence of the slurry properties including the boiling point of solvent, viscosity, and surface tension was taken into account.

The variation of dielectric properties with $\mathrm{TiO}_{2}$ content in PVP is shown in Table 1. The dielectric constant of the NC gate dielectric is significantly enhanced with raising $\mathrm{TiO}_{2}$ nanoparticles content in PVP. This result is associated with a greater dispersion and separation of high-k particles to enhance the equivalent parallel capacitance.

Figure 2 shows the leakage current and dielectric constant of the nanocomposite films based on PVP polymer matrices with different $\mathrm{TiO}_{2}$ nanoparticles concentration. The leakage current density of the insulator layers was deteriorating with increasing the $\mathrm{TiO}_{2}$ content in the MIM structure. The comparison between leakage current and leakage current density is based on the fact that electric field is $1.25 \mathrm{MV} / \mathrm{cm}$ (applied bias/thickness of insulation layer). $E_{B}$ is defined as the electric field at which the gate dielectric leakage current density exceeds $10^{-6} \mathrm{~A} / \mathrm{cm}^{2}$. $E_{B}$ was around $2.12 \mathrm{MV} / \mathrm{cm}$ at $1 \mathrm{wt} \%$ of doping and down to $1.65 \mathrm{MV} / \mathrm{cm}$ at $3 \mathrm{wt} \%$. This result is attributed to the enhancement of leakage conduction path related to the surface roughness and defect states in the interface between active and insulator layers [10] which was produced by higher inorganic content with lower energy gap in the wide-gap polymer matrix. The performance of leakage current of the gate dielectric would reflect the current-on/off ratio $\left(I_{\text {on } / \text { off }}\right)$ of the OTFT device. The corresponding AFM images of the neat PVP, $\mathrm{PVP}+1 \mathrm{wt} \% \mathrm{TiO}_{2}, \mathrm{PVP}+3 \mathrm{wt} \% \mathrm{TiO}_{2}$, and $\mathrm{PVP}+5 \mathrm{wt} \%$ $\mathrm{TiO}_{2}$ nanocomposite films are shown in Figures 7(a), 7(b), $7(\mathrm{c})$, and $7(\mathrm{~d})$. There is an obvious difference in morphology between the neat and nanocomposite films.

However, the increasing roughness of the NC-films due to raising $\mathrm{TiO}_{2}$ solid content in NC-drops results in degenerating liquidity of the film formed by inkjet printing on glass substrate.

Because the film-forming mechanism of NC-film by inkjet printing is different from spin coating (SPC), the degree of inner high-k particle distribution in polymer matrix affects electrical characteristics and qualities of NCfilms. Two mechanisms used to presume the dissimilarities 


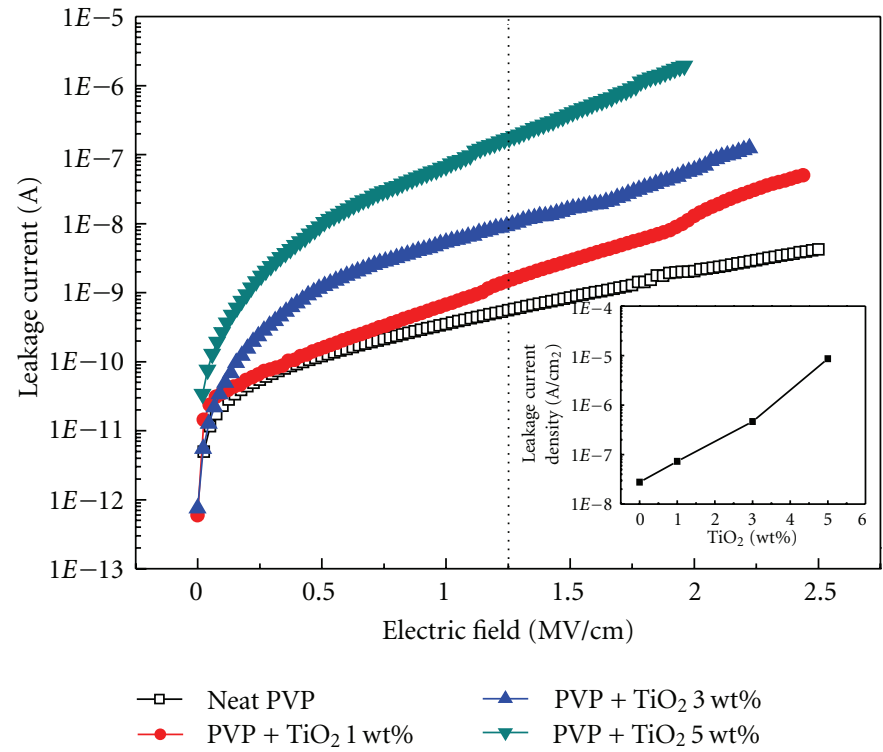

(a)

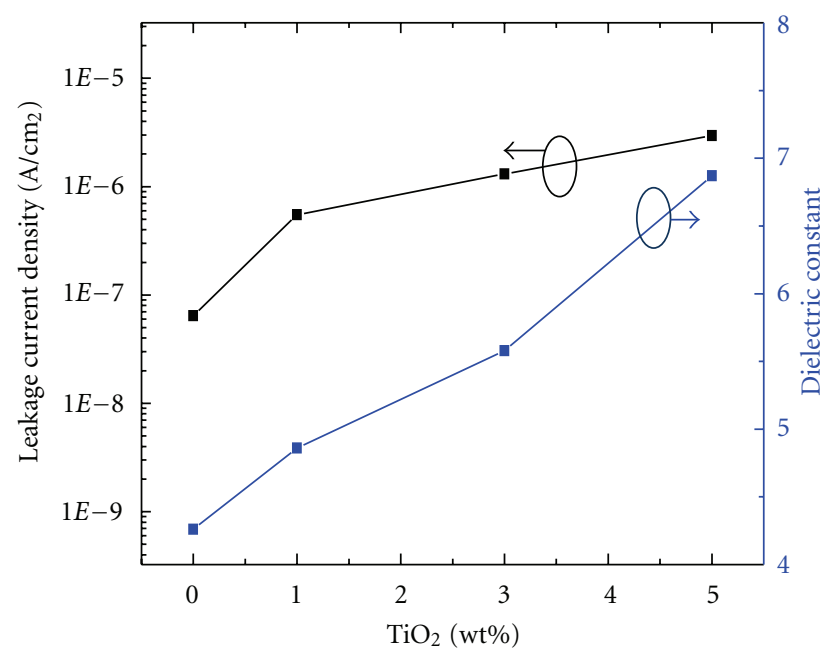

(b)

FIgURE 2: The plots of (a) $I-V$ characteristics and (b) relation of leakage current and surface roughness to TiO ${ }_{2}$ ratio in the MIM structure using nanocomposite insulators with various $\mathrm{TiO}_{2}$ concentration.

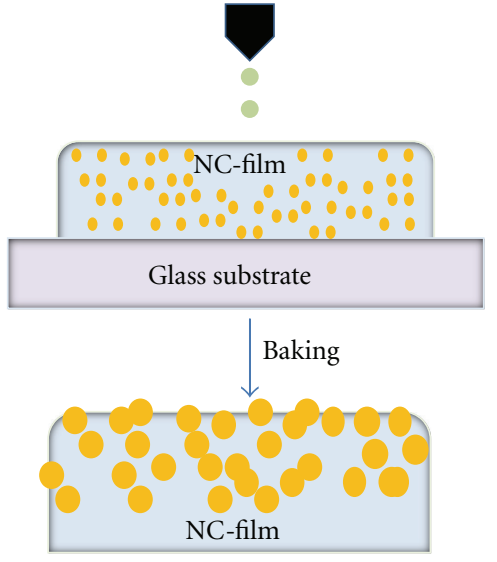

(a)

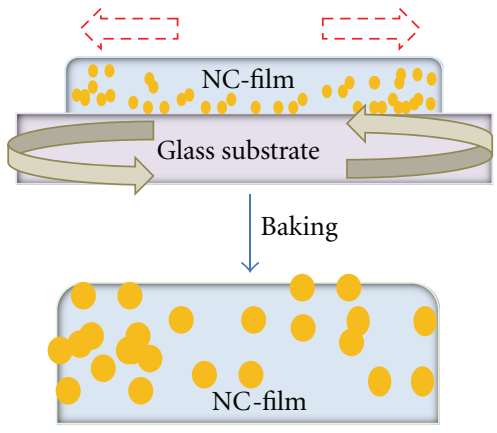

(b)

FIGURE 3: Film-forming mechanisms of NC-film: (a) inkjet printing (IJP); (b) spin coating (SPC).

between IJP and SPC methods are shown in Figure 3. The NC-inks prepared by pearl-milling has well dispersion, smaller nanoparticle size than ball-milling, and more solid content in polymer, which resulted in enhancing dielectric constant to $(\mathrm{k}=6.87)$ evidently. Figure $3(\mathrm{~b})$ demonstrates that spin-coating the mixture of $\mathrm{TiO}_{2}$ in polymer matrix makes the high- $\mathrm{k}$ particles affected by the outward net force from spinning to assemble on the edge of the film. The particle shift reduce the solid content in the middle with lower dielectric constant, but the surface would be more smooth.

3.2. Electrical Properties of OTFTs with Nanocomposite Gate Dielectric. The transfer curve and square root $I_{D S}$ versus gate voltage with 0 and $3 \mathrm{wt} \% \mathrm{TiO}_{2}$-blending of the $\mathrm{NC}$-dielectric pentacene OTFT in the saturation region $\left(V_{\mathrm{DS}}=-50 \mathrm{~V}\right)$ is shown in Figure 4 . The threshold voltage $\left(V_{\mathrm{T}}\right)$ for a $\mathrm{p}$ channel TFT device is related to the capacitance of the gate oxide, as given by (1) [11]

$$
V_{\mathrm{T}}=\left(\psi_{\mathrm{M}}-\psi_{\mathrm{S}}\right)-\frac{Q_{\mathrm{fix}}+Q_{\mathrm{it}}}{C_{\mathrm{OX}}}+\frac{\sqrt{4 q N_{\mathrm{A}} \varepsilon_{\mathrm{S}} \psi_{\mathrm{F}}}}{C_{\mathrm{OX}}}+2 \psi_{\mathrm{F}}
$$

Here, $\left(\psi_{\mathrm{M}}-\psi_{\mathrm{S}}\right)$ is the potential difference in the work function of the gate metal and the semiconductor. $Q_{\text {fix }}$ and $Q_{i t}$ is the fixed and interface trap charge density, respectively. $\psi_{\mathrm{F}}$ is the work function difference between the Fermi level and the intrinsic Fermi level, $q$ is the magnitude of electronic charge, $N_{\mathrm{A}}$ is the acceptor impurity concentration, $\varepsilon_{S}$ is dielectric permittivity of semiconductor, 
TABLE 1: The properties of MIM with PVP insulators with different $\mathrm{TiO}_{2}$-blending concentration by IJP.

\begin{tabular}{lcccc}
\hline Slurry & Pure PVP & $\mathrm{PVP}+1 \mathrm{wt} \% \mathrm{TiO}_{2}$ & $\mathrm{PVP}^{+3} \mathrm{wt} \% \mathrm{TiO}_{2}$ & $\mathrm{PVP}^{2} 5 \mathrm{wt} \% \mathrm{TiO}{ }_{2}$ \\
\hline Thickness $(\mathrm{nm})$ & 500 & 450 & 460 & 490 \\
Roughness $(\mathrm{nm})$ & 0.681 & 4.704 & 9.276 & 17.257 \\
Leakage current density $\left(\mathrm{A} / \mathrm{cm}^{2}\right)$ & $6.45 \times 10^{-8}($ at $63 \mathrm{~V})$ & $5.50 \times 10^{-7}($ at $57 \mathrm{~V})$ & $1.31 \times 10^{-6}($ at $58 \mathrm{~V})$ & $2.95 \times 10^{-6}($ at $62 \mathrm{~V})$ \\
Dielectric constant & 4.26 & 4.86 & 5.58 & 6.87 \\
\hline
\end{tabular}

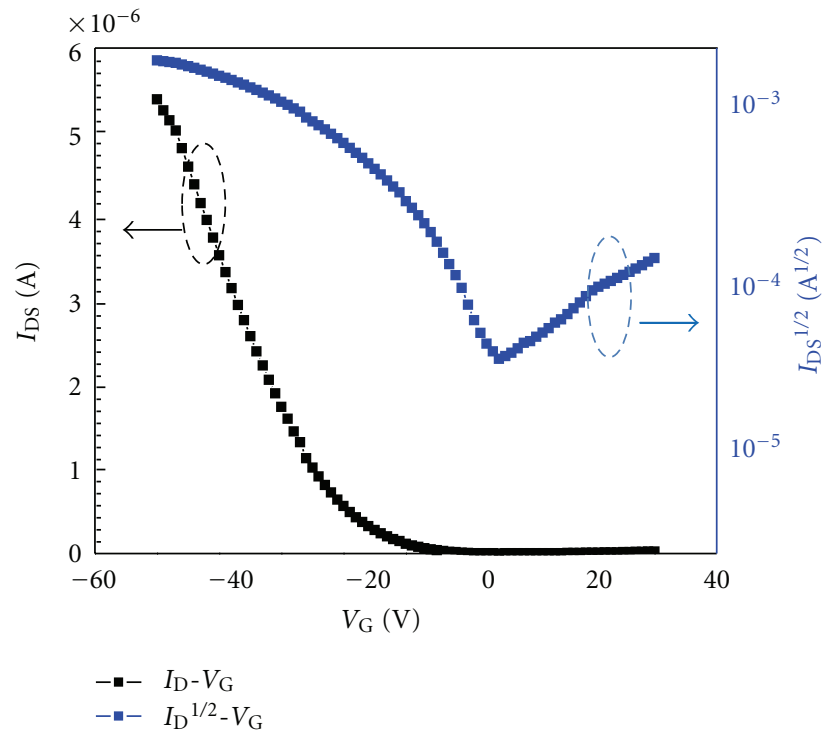

FIGURE 4: Transfer characteristics in saturation region for pentacene TFTs deposited on the $\mathrm{PVP}_{-} \mathrm{TiO}_{2}$ nanocomposite gate dielectric insulator with $3 \mathrm{wt} \%$ of $\mathrm{TiO}_{2}$ contents $\left(V_{\mathrm{D}}=-50 \mathrm{~V}\right)$.

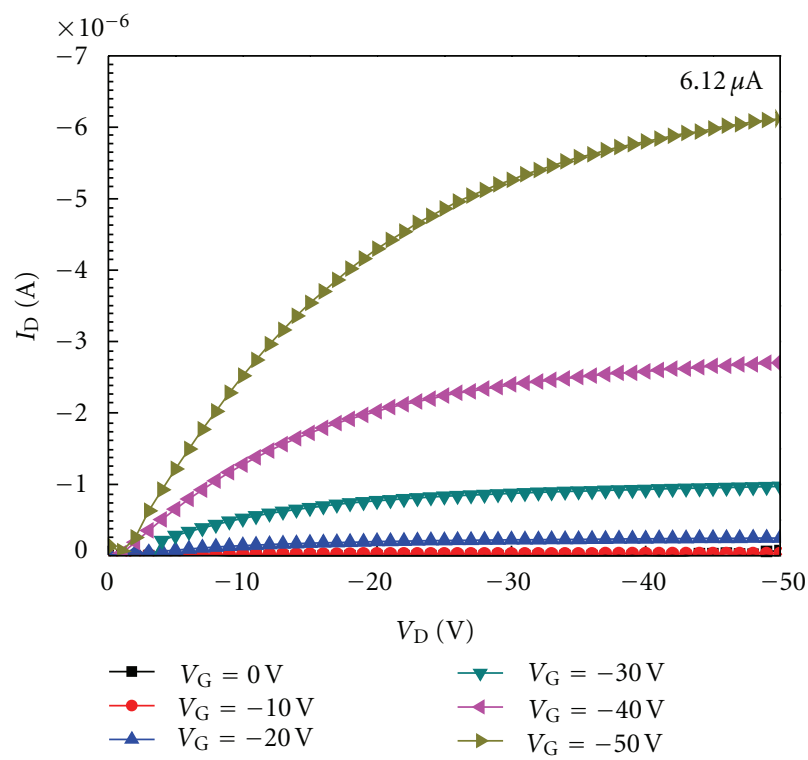

FIGURE 5: Characteristics of $I_{\mathrm{DS}}-V_{\mathrm{DS}}$ for pentacene-based TFTs deposited on the $\mathrm{PVP}-\mathrm{TiO}_{2}$ nanocomposite gate dielectric insulator with $\mathrm{TiO}_{2}$ contents: $3 \mathrm{wt} \%$ (color line). For the device, the drain voltage $\left(V_{\mathrm{DS}}\right)$ was swept from 0 to $-50 \mathrm{~V}$, and the gate voltage $\left(V_{\mathrm{GS}}\right)$ was fixed at $0,-10,-20,-30,-40$, and $-50 \mathrm{~V}$ for each $V_{\mathrm{DS}}$ sweep.

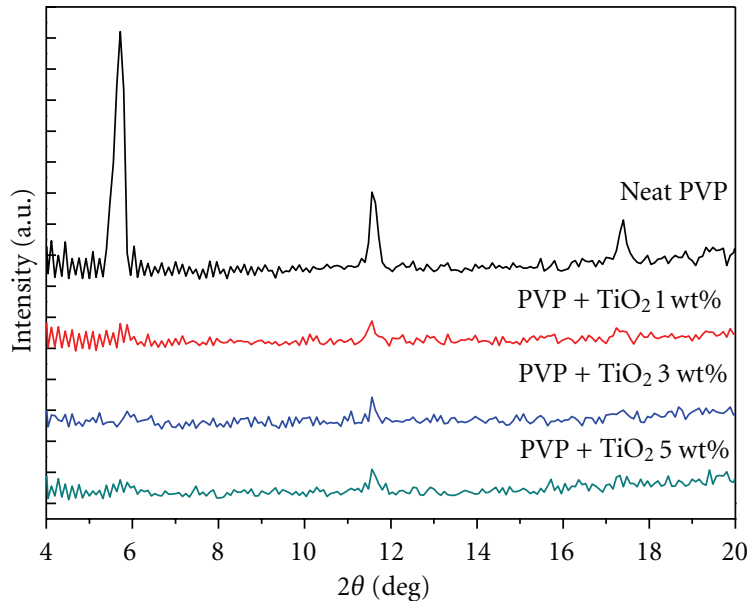

Figure 6: X-ray diffraction patterns of pentacene films were deposited on NC-films with various doped content: (a) neat PVP $9 \mathrm{wt} \%$ (cross-linked); (b) $\mathrm{PVP}+\mathrm{TiO}_{2} 1 \mathrm{wt} \%$; (c) $\mathrm{PVP}+\mathrm{TiO}_{2} 3 \mathrm{wt} \%$; (d) $\mathrm{PVP}+\mathrm{TiO}_{2} 5 \mathrm{wt} \%$.

and $C_{\mathrm{ox}}$ is the capacitance per unit area of the gate oxide. $C_{\text {ox }}$ is proportional to the intrinsic dielectric constant of the material. For working under a lower operating voltage $\left(V_{\mathrm{G}}\right)$, one solution is to increase the dielectric constant of the gate insulator of TFT by (1). On both increasing $V_{\mathrm{G}}$ and $V_{\mathrm{D}}$, the electrical transport properties in the saturation regime can be calculated by (2) [12]

$$
I_{\mathrm{DS}(\text { sat })}=\left(C_{\mathrm{i}} \frac{W}{L}\right) \mu_{\text {sat }}\left(V_{\mathrm{G}}-V_{\mathrm{T}}\right)^{2} .
$$

In (2), $I_{\mathrm{DS}(\text { sat })}$ is the saturation drain current, $\mu_{\text {sat }}$ is the fieldeffect saturation carrier mobility of the semiconductor, $C_{\mathrm{i}}$ is the capacitance per unit area of the insulator layer, $W$ is the channel width, and $L$ is the channel length. With $9 \mathrm{wt} \%$ of the polymer concentration, dielectric constant of the nanocomposite $\mathrm{PVP}+\mathrm{TiO}_{2}-3 \mathrm{wt} \%$ films are raised from 4.26 to 5.58. Owing to the gate dielectric with higher dielectric constant, the polarization in the interface between active and insulator layers can be enhanced, causing a stronger accumulation of charged carriers in the active channel to increase the output current of OTFT device. When the concentration increases to $5 \mathrm{wt} \%, V_{\text {th }}$ slightly reduces due to higher roughness which traps the carrier and the present of $\mathrm{TiO}_{2}$ nanoparticles which probably induces the recombination in the channel [13]. Table 2 summarizes electrical properties of those devices, which indicate that high $C_{\mathrm{OX}}$ redounds significantly to higher mobility and lower operating voltage, whereas reduces current-on/off ratios slightly. Consequently, the pentacene-TFT based on the NC 


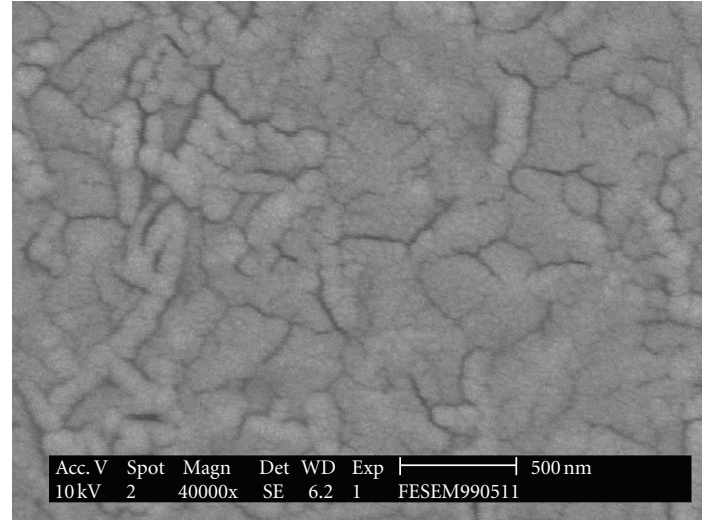

(a)

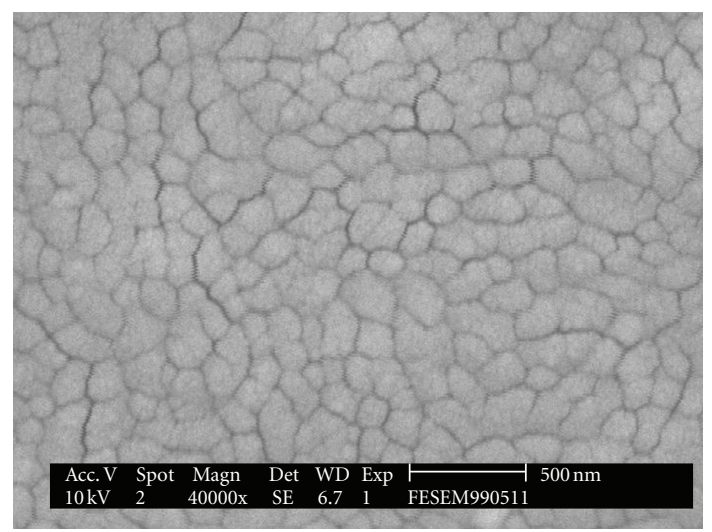

(c)

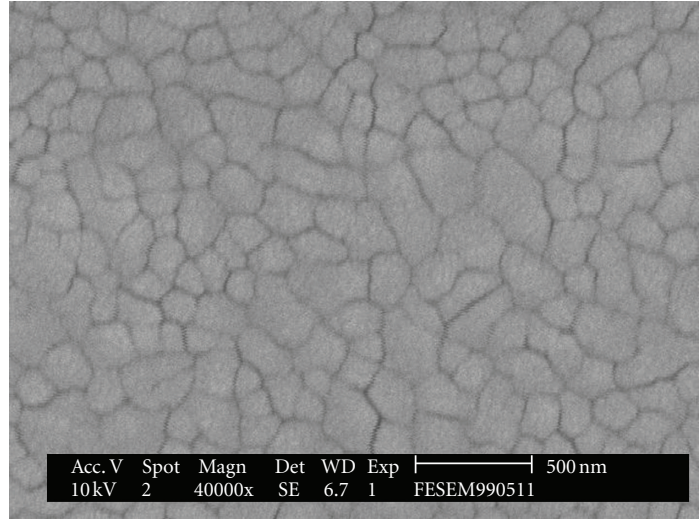

(b)

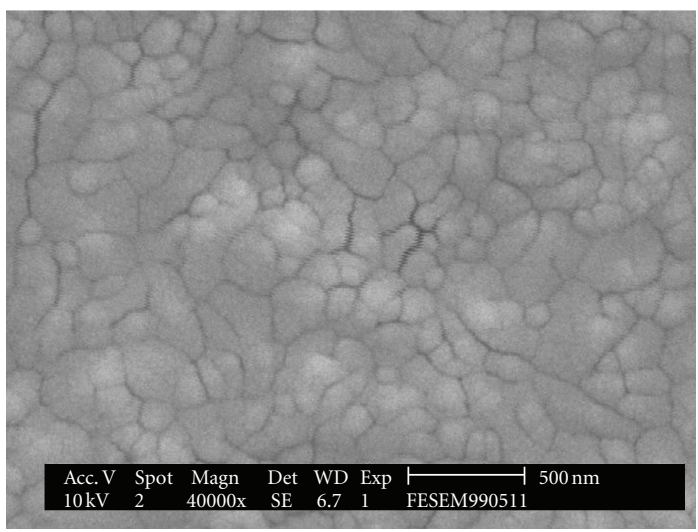

(d)

Figure 7: SEM photograph of pentacene films on NC-films with various doped content: (a) neat PVP $9 \mathrm{wt} \%$ (cross-linked), (b) PVP+TiO 2 $1 \mathrm{wt} \%$, (c) $\mathrm{PVP}+\mathrm{TiO}_{2} 3 \mathrm{wt} \%$, and (d) $\mathrm{PVP}+\mathrm{TiO}_{2} 5 \mathrm{wt} \%$.

gate dielectric by inkjet printing has demonstrated a higher field-effect saturation mobility of $0.58 \mathrm{~cm}^{2} / \mathrm{Vs}$, an on/off, ratio of about $3.8 \times 10^{3}$, and a lower threshold voltage under $V_{\text {th }}=-5.4 \mathrm{~V}$. Obviously, a positive effect of NC-dielectric ink on the saturation mobility enhancement was observed with the addition of $\mathrm{TiO}_{2}$ in Figure 5. Nevertheless, a higher leakage current would cause a higher output current of the device in the off-state.

\subsection{The Structure Characterization of Pentacene Film on the} NC-Dielectric Films. Figure 6 shows the X-ray diffraction (XRD) pattern of the pentacene films on NC-films with various doping contents. We observed a (002) phase in the XRD pattern of the films, which indicated that those sample remained thin-film phase. Furthermore, no evident peak of (001) phase in NC-film patterns was found, which suggested that great crystalline quality is one of the key factor for OTFT device performance [14].

From Figure 7(a), one can found that the grain size of the pentacene deposited on the printed neat-PVP film is relatively larger than pentacene films on NC-films, and the surface (Figure 7(a)) is closed to lamella morphology. Some factors reported in literatures for improving carrier transport are in connection with the film growth and quality, including lower degree of crystallinity, smaller crystalline domains, lower degree of order, and lower angle grain boundaries [1517].

In this work, Raman spectra were carried out to measure the coupling degree of intermolecular in pentacene thin films and investigate the carrier transport. Figure 8 shows Raman spectra of pentacene films on the NC-films with different doping concentrations and the relationship between intensity ratio and carrier nobilities. The Raman bands were clearly obtained in Figure 8(a). The two peaks of 1179,1158 , and the band in the vicinity of $1155-1158 \mathrm{~cm}^{-1}$ are attributed to the in-plane vibrations of the pentacene molecular and Davydov splitting, respectively [18]. The cause of the splitting is the energy difference by the symmetry of the intermolecular vibration coupling, which is in connection with the intermolecular interaction energy [19]. In Figure 8(a), larger intensity ratio of 1155 and $1158 \mathrm{~cm}^{-1}$ from the pentacene thin film deposited onto the NC-film (3wt\%) suggested that the direction of pentacene molecules arrangement in a lattice is better, which is beneficial to the device characteristics of OTFTs [19]. The stretching of C-C in the spectrum signal is at $1179 \mathrm{~cm}^{-1}$, which have smaller full width at half maximum (FWHM) from the pentacene film on printed NC-film with $3 \mathrm{wt} \%$ doped. It suggested that the pentacene thin film was deposited uniformly to exhibit lower relaxation energy [20-22]. Figure 8(b) demonstrates 


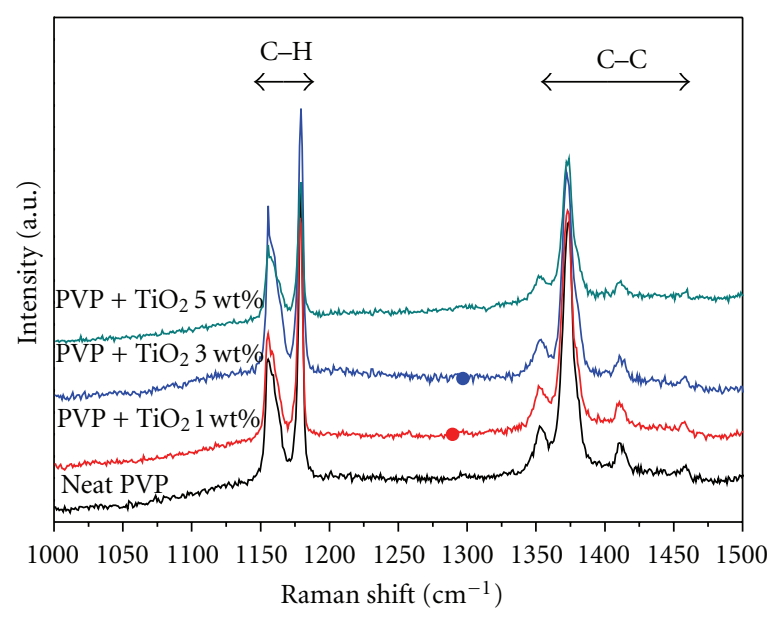

(a)

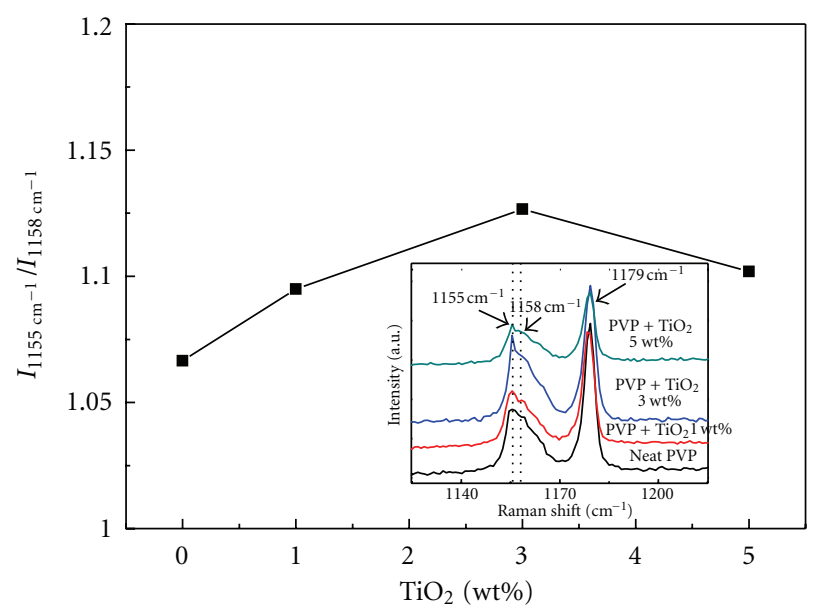

(b)

FIGURE 8: (a) Raman spectrum for pentacene films on printed NC-films; (b) Intensity ratio of 1155 and $1158 \mathrm{~cm}^{-1}$ with various doped content.

TABLE 2: Electrical characteristics of thermally pentacene TFTs prepared with various doping concentration whose nanocomposite insulators were fabricated by IJP and SPC.

\begin{tabular}{|c|c|c|c|c|c|}
\hline & $V_{\text {th }}(\mathrm{V})$ & On/Off ratio & Mobility $\left(\mathrm{cm}^{2} / \mathrm{Vs}\right)$ & $C_{\mathrm{ox}}\left(\mathrm{pF} / \mathrm{mm}^{2}\right)$ & S.S. (V/decade) \\
\hline $\mathrm{PVP}+\mathrm{TiO}_{2} 3 \mathrm{wt} \%$ (spin-coating) & -7.5 & $10^{7}$ & 0.53 & 90 & 1.9 \\
\hline neat PVP9 wt\% (cross-linked) & -9.1 & $7 \times 10^{3}$ & 0.23 & 75 & 5.6 \\
\hline $\mathrm{PVP}+\mathrm{TiO}_{2} 1 \mathrm{wt} \%$ & -7.3 & $4.5 \times 10^{3}$ & 0.42 & 94 & 5.3 \\
\hline $\mathrm{PVP}+\mathrm{TiO}_{2} 3 \mathrm{wt} \%$ & -5.4 & $3.8 \times 10^{3}$ & 0.58 & 107 & 5.6 \\
\hline $\mathrm{PVP}+\mathrm{TiO}_{2} 5 \mathrm{wt} \%$ & -6.6 & $3.5 \times 10^{3}$ & 0.49 & 124 & 5.7 \\
\hline
\end{tabular}

that raising the intermolecular coupling would enhance the overlap of $\pi$-conjugated electron cloud, which improves the carrier transport in the pentacene thin film.

\section{Conclusions}

In conclusion, we have made good use of pearl milling to prepare high-k nanocomposite inks and fabricated directlyprintable gate dielectric film for OTFT using inkjet printing. The nano- $\mathrm{TiO}_{2}$ particles were well dispersed, more effectively milled to nanoscale in the polymeric matrix, and then micronozzle-jetted successfully. In our work, the summary of film-forming mechanisms and the relationship between pentacene molecular vibration energy on NC-films and carrier transport are presented below.

(1) High capacitance of gate oxide can induce more carriers to accumulate in the channel between the electrodes of source and drain by improving the polarization, and then reduce the threshold voltage. The inkjet printing mechanism leads to the good distribution of high- $\mathrm{TiO}_{2}$ in polymer matrix, which is beneficial to maintain higher solid concentration in the dielectric and enhance the dielectric constant effectively.

(2) By inkjet printing the NC-gate dielectric, the NCgate pentacene-TFT demonstrated a higher fieldeffect saturation mobility of $0.58 \mathrm{~cm}^{2} / \mathrm{Vs}$ with an on/off ratio of $3.8 \times 10^{3}$ and a lower threshold voltage under $V_{\text {th }}=-5.4 \mathrm{~V}$. From Raman spectroscopy, larger intensity ratio of 1155 and $1158 \mathrm{~cm}^{-1}$ from the pentacene thin film corresponding to an excellent characteristic of OTFTs. Therefore, nanocomposite inks are expected to implement low-cost, heavy blending functional materials such as high- $\mathrm{k}$ dielectrics by using a simple solution-based fabrication process, which would extend the applications to active layers and conducting films to achieve all printed electronic devices in the future.

\section{Acknowledgement}

The authors would like to acknowledge financial support by R.O.C. of the National Science Council under Grant no. NSC 98-3114-E-110-003.

\section{References}

[1] G. Horowitz, M. Mottaghi, P. Lang et al., "On the crucial role of the insulator-semiconductor interface in organic thin-film transistors," in 5th Organic Field-Effect Transistors V, vol. 6336, article 63360G of Proceedings of SPIE, San Diego, Calif, USA, August 2006.

[2] W. H. Lee, C. C. Wang, and J. C. Ho, "Influence of nanocomposite gate dielectrics on OTFT characteristics," Thin Solid Films, vol. 517, no. 17, pp. 5305-5310, 2009. 
[3] W.-H. Lee, C.-C. Wang, W.-T. Chen, and J.-C. Ho, "Characteristic of organic thin film transistor with a high-k insulator of nano- $\mathrm{TiO}_{2}$ and polyimide blend," Japanese Journal of Applied Physics, vol. 47, no. 12, pp. 8955-8960, 2008.

[4] F. C. Chen, C. S. Chuang, Y. S. Lin, L. J. Kung, T. H. Chen, and H. P. D. Shieh, "Low-voltage organic thin-film transistors with polymeric nanocomposite dielectrics," Organic Electronics, vol. 7, no. 5, pp. 435-439, 2006.

[5] F. C. Chen, C. W. Chu, J. He, Y. Yang, and J. L. Lin, "Organic thin-film transistors with nanocomposite dielectric gate insulator," Applied Physics Letters, vol. 85, no. 15, pp. 3295-3297, 2004.

[6] C. Jung, A. Maliakal, A. Sidorenko, and T. Siegrist, "Pentacenebased thin film transistors with titanium oxide-polystyrene/ polystyrene insulator blends: high mobility on high $K$ dielectric films," Applied Physics Letters, vol. 90, no. 6, Article ID 062111, 2007.

[7] P. Kim, X.-H. Zhang, B. Domercq et al., "Solution-processible high-permittivity nanocomposite gate insulators for organic field-effect transistors," Applied Physics Letters, vol. 93, no. 1, Article ID 013302, 2008.

[8] A. K. Sen and J. Darabi, "Droplet ejection performance of a monolithic thermal inkjet print head," Journal of Micromechanics and Microengineering, vol. 17, no. 8, article 002, pp. 1420-1427, 2007.

[9] J. H. Werth, M. Linsenbühler, S. M. Dammer et al., "Agglomeration of charged nanopowders in suspensions," Powder Technology, vol. 133, no. 1-3, pp. 106-112, 2003.

[10] A. Rockett, The Materials Science of Semiconductors, Springer, New York, NY, USA, 2008.

[11] H. Watanabe, S. Ando, H. Aota, M. Dainin, Y. J. Chun, and $\mathrm{K}$. Taniguchi, "CMOS voltage reference based on gate work function differences in poly-Si controlled by conductivity type and impurity concentration," IEEE Journal of Solid-State Circuits, vol. 38, no. 6, pp. 987-994, 2003.

[12] G. Horowitz, "Organic field-effect transistors," Advanced Materials, vol. 10, no. 5, pp. 365-377, 1998.

[13] C. S. Chuang, F. C. Chen, and H. P. D. Shieh, "Organic thinfilm transistors with reduced photosensitivity," Organic Electronics, vol. 8, no. 6, pp. 767-772, 2007.

[14] I. Yagi, K. Tsukagoshi, and Y. Aoyagi, "Growth control of pentacene films on $\mathrm{SiO}_{2} / \mathrm{Si}$ substrates towards formation of flat conduction layers," Thin Solid Films, vol. 467, no. 1-2, pp. 168$171,2004$.

[15] L. Torsi, A. Dodabalapur, L. J. Rothberg, A. W. P. Fung, and H. E. Katz, "Intrinsic transport properties and performance limits of organic field-effect transistors," Science, vol. 272, no. 5267, pp. 1462-1464, 1996.

[16] T. W. Kelley, D. V. Muyres, F. P. Baude, T. P. Smith, and T. D. Jones, "High performance organic. Thin film transistors," Materials Research Society Symposium Proceedings, vol. 771, pp. L6.5.1-L6.5.10, 2003.

[17] M. Shtein, J. Mapel, J. B. Benziger, and S. R. Forrest, "Effects of film morphology and gate dielectric surface preparation on the electrical characteristics of organic-vapor-phase-deposited pentacene thin-film transistors," Applied Physics Letters, vol. 81, no. 2, p. 268, 2002.

[18] A. S. Davydov, Theory of Molecular Excitons, McGraw-Hill, New York, NY, USA, 1971.

[19] W. Y. Chou and H. L. Cheng, "An orientation-controlled pentacene film aligned by photoaligned polyimide for organic thin-film transistor applications," Advanced Functional Materials, vol. 14, no. 8, pp. 811-815, 2004.
[20] H. L. Cheng, W. Y. Chou, C. W. Kuo et al., "Influence of electric field on microstructures of pentacene thin films in field-effect transistors," Advanced Functional Materials, vol. 18, no. 2, pp. 285-293, 2008.

[21] H. L. Cheng, W. Y. Chou, C. W. Kuo, F. C. Tang, and Y. W. Wang, "Electric field-induced structural changes in pentacene-based organic thin-film transistors studied by in situ micro-Raman spectroscopy," Applied Physics Letters, vol. 88, no. 16, Article ID 161918, 2006.

[22] H. L. Cheng, X. W. Liang, W. Y. Chou et al., "Raman spectroscopy applied to reveal polycrystalline grain structures and carrier transport properties of organic semiconductor films: application to pentacene-based organic transistors," Organic Electronics, vol. 10, no. 2, pp. 289-298, 2009. 

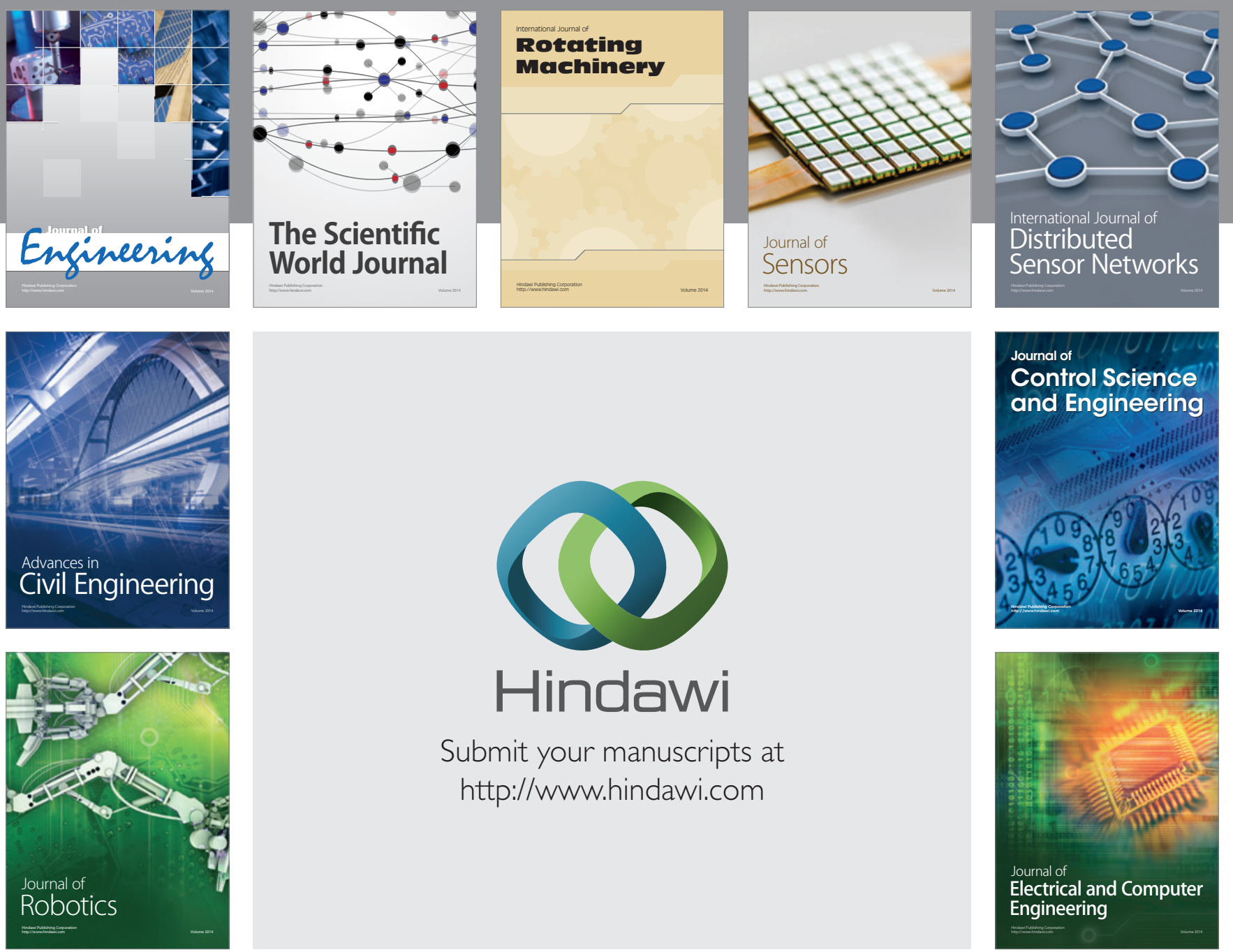

Submit your manuscripts at

http://www.hindawi.com
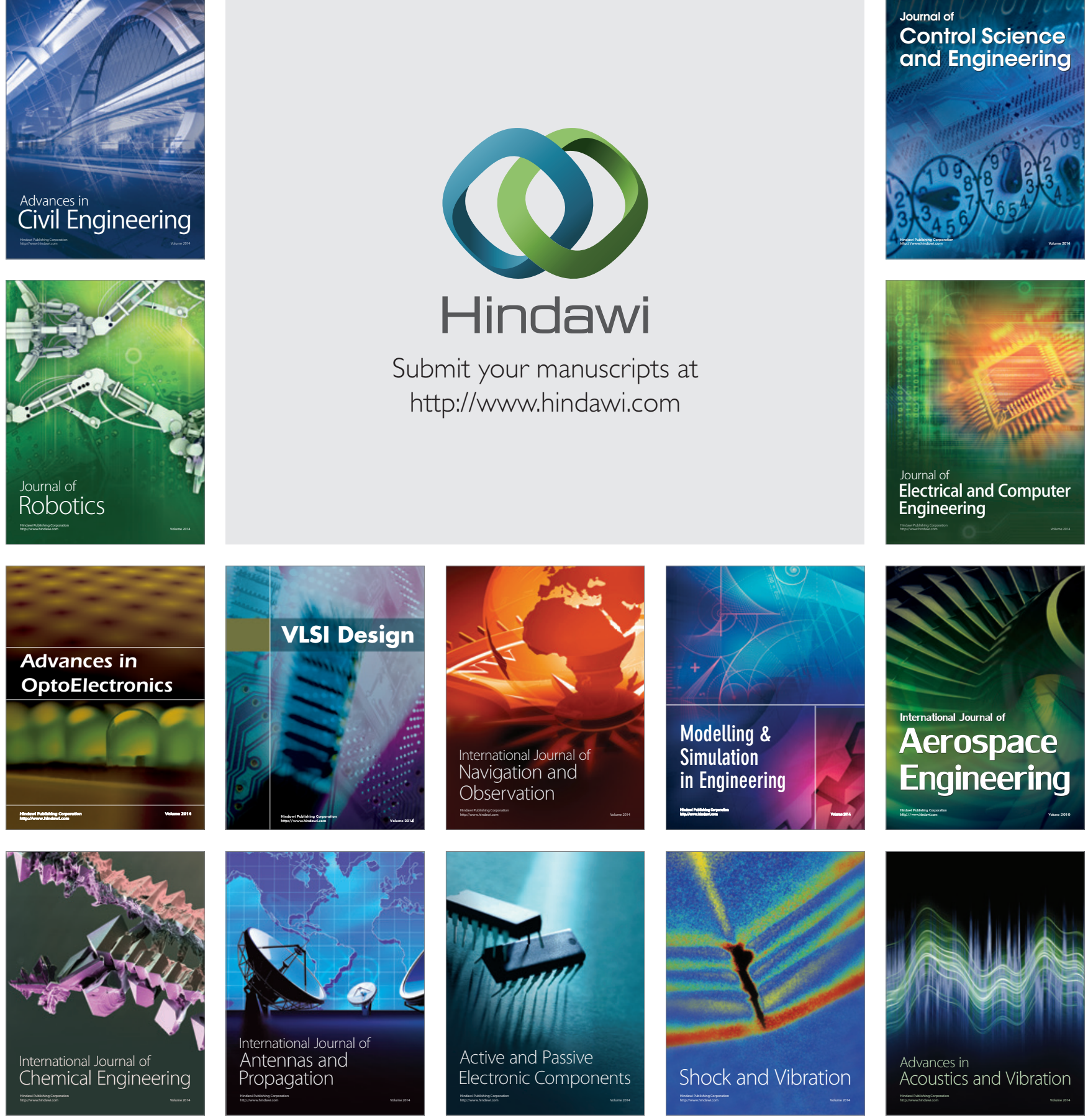